\title{
Ensinar gêneros?
}

Tânia Maris de Azevedo*

\section{Resumo}

Ensinar a ler e escrever parece, mesmo que subliminarmente assumido, ser o fim maior do ensino de língua materna na educação básica brasileira. A despeito de toda a produção científico-pedagógica e linguística existente sobre alfabetização e letramento, tenciono, neste artigo, levantar algumas questões e desencadear mais algumas discussões acerca da aprendizagem e, como decorrência, do ensino da leitura e da produção escrita de textos/discursos. Será o ensino de gêneros textuais/discursivos o melhor caminho para o desenvolvimento das complexas habilidades de ler e escrever? O que precisa ser ensinado para que essas habilidades sejam, ao menos, satisfatoriamente desenvolvidas, gêneros, tipos, sequências, modos de organização de texto/discurso? Essas são algumas das perguntas norteadoras da reflexão aqui apresentada à luz de autores como Saussure, Benveniste, Bakhtin e Ducrot.

Palavras-chave: Ensino de língua materna. Leitura e escrita. Texto e discurso. Gêneros textuais/discursivos.

\section{Introdução}

Aprender a ler e a escrever pelo ensino de língua materna que se tem atualmente na maioria das escolas de Educação Básica, sejam elas da rede pública ou particular de ensino, requer que o aluno tenha aptidões sobrenaturais ou, no mínimo, mágicas. Explico: os alunos após, e mesmo durante, o chamado período de alfabetização são inseridos (e esse foi o termo mais suave que encontrei) no reino da gramática normativa da língua portuguesa, classificando palavras e frases, ou partes delas, conjugando verbos, flexionando substantivos, adjetivos, memorizando listas de coletivos, conjunções, preposições, enfim, dissecando um grande e aterrorizante monstro chamado

* Doutora em Letras - Linguística Aplicada, pela PUC-RS, professora pesquisadora do Programa de Doutorado em Letras - Associação Ampla UCS/UniRitter, do Programa de Pós-Graduação em Educação - Mestrado e do curso de Letras - Licenciatura, da Universidade de Caxias do Sul - RS. E-mail: tmazeved@ucs.br.

Data de submissão: mar. 2014 - Data de aceite: abr. 2014

http://dx.doi.org/10.5335/rdes.v10i1.4098 
português. Depois que já estão "craques" nessa metalinguagem despregada de tudo e de todos, os professores dizem "pirlimpimpim" e ordenam que leiam vários textos, de muitos tipos, formas, gêneros e escrevam perfeitamente as ditas redações (não menos famigeradas habitantes do submundo escolar).

Além disso, quem disse que a língua normatizada pela gramática é a língua que usamos? Quem disse que a gramática normatizante de orações e períodos pode dar conta de entidades linguísticas mais complexas como o texto/discurso?

Bem, mas os tempos mudaram! É chegada a hora de experimentar a "nova" tendência no ensino de língua materna, a mais fashion na pedagogia linguística: vamos vestir o ensino com o look gêneros discursivos, by Bakhtin, ou gêneros textuais, by Bronckart. Então, malgrado o que dizem os linguistas que se debruçaram a estudar séria e exaustivamente o tema, passamos (nós, os professores de língua portuguesa) a trabalhar em sala de aula com notícias, reportagens, cartas, fábulas, enfim, uma gama de gêneros textuais/discursivos ${ }^{1}$, exigindo de nossos alunos que os diferenciem, principalmente quanto à forma, e que os dissequem tal qual o fazíamos (fazemos) com os chamados conteúdos gramaticais.

Isso quer dizer que sou contra o ensino de gêneros na educação básica? Muito pelo contrário, a discussão que estou tentando provocar diz respeito a mais esse modismo que a educação brasileira, no geral, segue, sem sequer questionar como o sujeito aprende a modalidade escrita de uma língua, sem buscar saber o que, de fato, implica saber ler e escrever proficientemente, ao menos na língua-mãe. E pior: como não estão devidamente inteirados do que seja aprender, aprender a ler e escrever ou mesmo do que sejam os tais gêneros, o que mais tem ocorrido é o que venho chamando gramaticalização dos gêneros textuais/ discursivos. Novamente, à semelhança do que é feito com a gramática normativa, o ensino de gêneros, longe de representar o ensino do uso da língua escrita, tem se resumido à informação sobre a configuração superficial de cada gênero e à reprodução dessa "formatação", na maioria das vezes fora de qualquer situação enunciativa, mesmo que simulada.

Acontece que ler e escrever são habilidades, portanto, do âmbito do saber fazer e, para que sejam desenvolvidas, pressupõem ação, não teorização. Em nada, ou para ser menos radical, em muito pouco contribui para um saber operacional, como o é o uso da língua escrita, informações que dizem respeito a configuração morfossintática ou textual/ discursiva dessa dada língua. Em outras palavras, pouco adianta para os alunos que os docentes falem sobre a língua, suas classes gramaticais, as funções sintáticas dos termos que a compõem ou o "desenho" estrutural de cada gênero, pois o uso escrito de uma língua requer, e não há redundância aqui, o uso escrito dessa língua, quer em atividades de leitura, quer de produção. 
E, ainda: se o ler e o escrever são habilidades, quem pode mediar tal desenvolvimento? Os professores que dominam as normas gramaticais? Os docentes que se apropriaram de várias teorias sobre gêneros textuais/discursivos? $\mathrm{Ou}$, como requer o desenvolvimento de qualquer saber operacional, aquele profissional que já desenvolveu em maior grau essas habilidades, aquele professor que já sabe ler e escrever proficuamente?

Por óbvio, a aprendizagem e o ensino são processos cuja complexidade não pode ser reduzida a esse quadro que esbocei. Muitas são as variáveis que intervêm no aprender e no ensinar, assim como nos processos de leitura e de escrita. Meu objetivo, mais do que caricaturar o ensino de língua portuguesa escrita, é o de chamar a atenção do leitor, seja o linguista, seja o professor, para a premência de repensar e qualificar ainda mais o objeto de aprendizagem na disciplina de Português no currículo da educação básica. Aliás, não é por nada que esse nível de instrução chama-se básica, pois o que se espera de um cidadão que ultrapasse esse nível é que, no mínimo, saiba interagir, por escrito e de forma qualificada, com os demais membros da sociedade.

Mas o leitor que chegou até aqui deve estar se perguntando o que fazer, então, para que os usuários da língua portuguesa oral aprendam a usá-la também na modalidade escrita? Pretendo discutir o que fazer, mas, principalmente, o que priorizar no ensino de língua materna escrita. Sim, a meu ver, o que distingue um professor de qualquer outro profissional não é o fato de o primeiro "saber" ensinar, pois, infelizmente já é consenso que muitos profissionais "não professores" sabem ensinar melhor do que muitos daqueles que exercem a docência. $O$ diferencial de ser realmente professor é saber: (a) como o sujeito aprende, isto é, como esse sujeito acessa e processa informações, forma conceitos, constrói conhecimentos, desenvolve competências e habilidades, constitui atitudes e valores; (b) como hierarquizar prioridades para mediar eficazmente a interação do sujeito conhecedor com o objeto de conhecimento e com os outros sujeitos; (c) como planejar situações-problema capazes de, por um lado, criar a necessidade de aprender e, por outro, de munir o aluno das informações e dos instrumentos necessários a tal aprendizagem; (d) como transpor didaticamente o saber histórica e cientificamente produzido para torná-lo acessível e compreensível ao aprendiz; e (e) como avaliar o desempenho do aluno de modo a verificar a aprendizagem efetivamente consolidada.

Evidentemente, não tenho a pretensão de tratar, ainda mais com os limites próprios de um artigo como este, de toda a complexidade inerente ao ensino da leitura e da produção escrita. Minha intenção resume-se a examinar um pouco mais de perto as noções de texto, discurso e gênero, à luz de alguns dos alicerces da ciência Linguística - Saussure, Benveniste, Bakhtin - e de um estudioso mais 
contemporâneo - Oswald Ducrot - para fundamentar uma alternativa potencialmente capaz de contribuir para a qualificação do ensino da leitura e da escrita em língua portuguesa, na educação básica.

A ideia que trago à discussão é a de que, ao menos no ensino fundamental, antes de serem ensinados os gêneros de texto ${ }^{2}$, o próprio texto seja objeto de aprendizagem, quer em termos de leitura, quer de produção. É a explicar e fundamentar essa proposição que se destina este artigo. Começo, então, por revisitar brevemente os conceitos que o embasam.

\section{Voltando aos fundamentos da Linguística}

Pretendo fundar minha proposta de trabalho com texto na educação básica, partindo de um pressuposto saussuriano muito bem apresentado por Ducrot (1987, p. 64), a oposição metodológica língua-fala ${ }^{3}$, isto é, a "distinção clássica entre o objeto construído pelo pesquisador e o dado do qual esse objeto deve fornecer uma explicação". Dito de outra forma, Saussure, ao opor lingua e fala, faz da primeira o constructo teórico destinado a explicar, por abstração, o fenômeno linguístico, o que de fato ocorre quando um sujeito enuncia algo, seja oralmente, seja por escrito. Assim, a língua saussuriana é o sistema de signos construído pelo linguista a partir da fala, do que pode ser observado, ouvido e/ou lido, quando da interação humana.
Segundo Saussure (ELG, 2004, p. 21 - grifos do autor), é necessário distinguir "os fenômenos internos ou de consciência e os fenômenos externos, diretamente detectáveis". Os fenômenos "de consciência" são as entidades de nível abstrato ${ }^{4}$, ou seja, deduzidas teoricamente (nesse caso a língua ${ }^{5}$, a organização sistêmica de signos) diferentemente das entidades de nível concreto, dos fenômenos "diretamente detectáveis" (aqui, a fala, a realização da língua, a atualização do sistema linguístico). Vê-se, concordando com Ducrot (1987), que Saussure faz uso da tradicional (sem qualquer tom pejorativo, muito pelo contrário) oposição dialética greco-latina entre teoria e prática.

NB.: Acredito que a oposição teorial prática tem norteado, senão todas, a maior parte das discussões pedagógicas, quer no que diz respeito à aprendizagem, quer no que se refere ao ensino. $\mathrm{O}$ que me parece é que esse debate tem preterido justamente o essencial dessa oposição, seu caráter dialético (o que, aliás, também é válido para a oposição língua / fala). Tem sido muito questionada a "ordem", a "sequência" em que teoria e prática devem ser didaticamente abordadas no contexto da educação formal: deve-se primeiro tratar da teoria existente em relação a determinado tópico de estudo para, depois, criar situações de aplicação, propor ao aluno atividades que visem à prática de tal teoria, ou, reversamente, oportunizar ao aprendiz contextos de ação, dos quais possam, por dedução, abstrair a teoria que os 
sustenta e explica? Talvez, estejamos diante de uma possível diferença entre oposição e divisão: saussurianamente falando, a oposição é uma inter-relação em que nenhum dos opostos pode ser visto, estudado separadamente; o movimento dialético de interdependência é inerente à oposição, logo, não se pode pensar em sequência, mas em relação teoria e prática, assim como ocorre entre língua e fala; não existem e, portanto, não se definem a não ser reciprocamente, fazendo uma analogia ao que Saussure diz da mais exata característica do signo linguístico, uma é o que a outra não é. Já a divisão permite uma separação entre o que está sendo cindido, autorizando estabelecer uma ordem, uma hierarquia, uma sequência entre as partes dissociadas. Assim, quando se estuda a morfologia de uma determinada língua, por exemplo, é necessário decompor as unidades linguísticas para entender seu processo de formação, analisar cada parte para compreender a constituição do todo, mas, mesmo assim, não se pode perder de vista a inter-relação dessas partes na composição da unidade. Ora, é justamente a natureza dialética da relação teoria / prática que propicia a aprendizagem, pois uma despregada da outra não faz o menor sentido, o conhecimento não é constituído somente de teoria ou de prática, mas da interdependência dessas dimensões. Enfim, como Morin (1999, p. 231) bem o coloca, "nossa única realidade imediata é a representação da realidade, e a nossa única realidade concebível é a nossa concepção da realidade", ou seja, não há, como pensam alguns professores, prática sem teoria, nem o inverso. Cabe aqui, porém, uma ressalva, em minha opinião, essencial. Como o uso proficiente de uma língua, oralmente e/ou por escrito, requer o desenvolvimento de habilidades (falar, compreender o que é ouvido, ler e escrever), a relação teoria / prática no ensino de língua é substancialmente diferente da que subjaz a outros componentes curriculares, como História, Geografia, Biologia, Química, Física, os quais pressupõem a formação de conceitos. E essa diferença reside em três pontos básicos: (a) no fato de que o estudo/a aprendizagem de uma língua se faz por meio da própria língua, ao passo que nas demais disciplinas a língua é usada para ensinar e aprender; (b) a teoria, no que tange ao ensinar/aprender uma língua, não é representada pela gramática normativa ou pela metalinguagem, mas pela reflexão referente ao uso dessa língua; trata-se de tomar consciência de diversos modos de realização do sistema linguístico em pauta, e não de ouvir falar sobre ele e nomear seus constituintes; e (c) não há desenvolvimento de habilidades sem a ação a ele inerente, ou seja, para aprender a usar uma língua, é necessário falar, ouvir (para compreender, claro), ler e escrever essa língua, logo, a prática precisa fazer-se presente em todas as situações de aprendizagem, algo como, ação / reflexão / ação. 
Voltemos, pois, à discussão anterior a respeito dos conceitos saussurianos que fundamentam minha proposta para o ensino de língua. No ELG (p. 237, grifos do autor), mais precisamente no que chamou de "Nota sobre o discurso", Saussure diz ${ }^{6}$ :

A língua é criada unicamente com vistas ao discurso, mas o que separa o discurso da língua, ou o que, em certo momento, permite dizer que a língua entra em ação como discurso?

[...] o discurso consiste, ainda que de forma rudimentar, e por vias que ignoramos, em afirmar um elo entre dois conceitos que se apresentam revestidos de forma linguística, ao passo que a língua apresenta previamente apenas conceitos isolados que esperam ser postos em relação entre eles para que exista significação de pensamento.

Por essa reflexão saussuriana, podemos ver que ele concebe discurso como língua em ação, ou seja, da esfera da fala, do uso, da realização do sistema linguístico. Mais que isso, o discurso, pelo que diz o autor, pressupõe a criação de um "elo" entre dois conceitos que, "revestidos de forma linguística", atualizam o sistema do qual fazem parte como "conceitos isolados”. Ainda: é pelo discurso e/ou no discurso que, para Saussure, a "significação de pensamento" ganha existência, justamente nas e pelas relações que são estabelecidas entre os conceitos quando da concretização da língua em discurso.

$\mathrm{Na}$ verdade, e como não poderia deixar de ser uma vez que opõe e não divide conceitos, Saussure não separa definitiva e rigidamente língua e fala, como o disseram muitos de seus oponen- tes, mas ao contrário, defende a ideia de que língua e fala são as duas faces da linguagem. No CLG, quando define o objeto da Linguística, Saussure (1995, p. 15) diz que "o fenômeno linguístico apresenta perpetuamente duas faces que se correspondem e das quais uma não vale senão pela outra”. E, em seguida (op. cit., p. 16), afirma ter a linguagem "um lado individual" (a fala) e "um lado social" (a língua), "sendo impossível conceber um sem o outro".

A indissociabilidade língua/fala, a que se refere Saussure, foi trazida neste estudo com os seguintes propósitos:

(a) referendar o que eu disse a respeito da diferença entre oposição e divisão;

(b) apresentar a visão saussuriana de discurso como língua em ação e com isso fundamentar minha ideia de que aprender a usar uma língua requer o desenvolvimento de habilidades, não a formação de conceitos;

(c) trazer à tona a oposição abstrato/ concreto, o que me servirá para defender minha proposta para o ensino de língua.

Outro linguista de cujos pressupostos teóricos me valho para embasar este conjunto de cogitações é Émile Benveniste, com os conceitos de língua, enunciação, enunciado e discurso.

Para esse teórico, língua é o "sistema que inter-relaciona valor distintivo das formas e valor referencial relativo à situação enunciativa." (FLORES et al. 2009, p. 150). Assim, Benveniste justifica sua definição de língua: 
$1^{0}$ ela se manifesta pela enunciação, que contém referência a uma situação dada; falar, [sic] é sempre falar de;

$2^{\underline{0}}$ ela consiste formalmente de unidades distintas, sendo que cada uma é um signo;

$3^{0}$ ela é produzida e recebida nos mesmos valores de referência por todos os membros de uma comunidade;

$4^{\circ}$ ela é a única atualização da comunicação intersubjetiva. (BENVENISTE, 1989, p. 63)

No PLG ${ }^{7}$ II, ao apresentar a formulação do seu "aparelho formal da enunciação", Benveniste (1989) concebe enunciação como um fenômeno comum a ponto de ser difícil distingui-lo do próprio sistema linguístico e, simultaneamente, imprescindível, chegando mesmo a não ser notado. Para ele, enunciação "é este colocar em funcionamento a língua por um ato individual de utilização" (BENVENISTE, 1989, p. 82), é o próprio ato de produzir um enunciado, a mobilização da língua que o locutor faz por sua conta, sob sua responsabilidade.

Ao tratar do enunciado, esse autor entende o produto situado da enunciação, isto é, o resultado do processo de enunciá-lo e contém em si pessoa, tempo e espaço. Um enunciado é produzido num dado lugar, num determinado momento, contexto em que a língua é mobilizada por um locutor. Na teoria benvenistiana, segundo Flores et al. (2009, p. 107), o enunciado é sinônimo de frase.

Benveniste incrementa a língua saussuriana com a enunciação, isto é, o sistema linguístico contém não somente os signos inter-relacionados solidariamente como também o próprio fato de o locutor mobilizar a língua para produzir enunciados e/ou discursos. Discurso em Benveniste é o resultado da atualização da língua cada vez que o locutor se diz eu.

Mais uma vez, temos aqui um linguista que não vê a língua como um fóssil a ser estudado pela arqueologia gramatical normativa, mas como um sistema dinâmico cujos constituintes e suas relações interdependentes são postos em ação por um locutor, num dado tempo, num determinado espaço para a interlocução, via enunciado/discurso.

Novamente, como em Saussure, vemos nas colocações benvenistianas o princípio da relação, a partir do qual uma unidade do sistema linguístico não tem qualquer realidade ou significação independentemente de sua recolocação no âmbito da organização de que é parte.

Ora, se como quer Benveniste, o discurso é o produto da atualização da língua por um locutor que se autorrefere como $e u$, aprender a usar eficazmente um sistema linguístico exige a produção e a recepção, oral e/ou escrita, de discursos, não de frases ou de palavras isoladamente e, menos ainda, aprender a categorização das unidades da língua.

Seguindo nessa trilha teórica, vejamos o que nos diz Bakhtin em relação ao conceito de discurso.

De acordo com Flores et al. (2009, p. 84), Bakhtin compreende discurso como "língua em sua integridade concreta e 
viva". Outra vez, por outra voz, vê-se a concepção de língua viva, concreta, em uso, e o autor a assimila a discurso, ou seja, não há língua se não houver a atualização dessa língua.

Na nota de rodapé da página que abre o capítulo "Gêneros do discurso", do livro Estética da criação verbal, o tradutor esclarece que optou por traduzir como enunciado o termo russo viskázivanie, já que Bakhtin o usa para referir tanto o processo quanto o produto da realização linguística: viskázivanie, então, diz respeito tanto à enunciação, como o ato de produção de um discurso, quanto a um discurso escrito. Esse alerta do tradutor foi trazido aqui como mais uma evidência de que o sistema linguístico, como algures já o disse Saussure, se não for posto em ação por um locutor para a produção de um discurso, não passa de uma virtualidade, uma possibilidade de língua.

Bakhtin (2003, p. 278), à semelhança de Saussure e Ducrot ${ }^{8}$, opõe as unidades da língua às unidades do discurso, as unidades abstratas às concretas. Assim, afirma que não são objetos de interlocução as unidades da língua, apenas as do discurso.

Não se intercambiam orações como se intercabiam palavras (em rigoroso sentido lingüístico) e grupos de palavras; intercambiam-se enunciados que são construídos com o auxílio das unidades da língua: palavras, combinações de palavras, orações; ademais, o enunciado pode ser construído a partir de uma oração, de uma palavra, por assim dizer, de uma unidade do discurso (predominantemente de uma réplica do diálogo), mas isso não leva uma unidade da língua a transformar-se em unidade da comunicação discursiva.
Fica sempre a pergunta que não quer calar: se é assim, por que, na escola, é dada tanta ênfase às unidades da língua e tão pouca, ou quase nenhuma, às unidades do discurso?

Falar em Bakhtin e não falar em gênero de discurso é quase uma heresia. Não pretendo, entretanto, aprofundar a discussão acerca desse conceito por crer que já se o tenha analisado quase exaustivamente. Vou me permitir apenas (para os objetivos que tenho com este artigo) mencionar que gênero, para esse estudioso (2003, p. 282, grifos do autor), são "formas relativamente estáveis e típicas de construção do todo", sendo o "todo" a que se refere Bakhtin o discurso.

Mesmo que tenha mobilizado esse conceito bakhtiniano de forma breve e superficial, não posso deixar de citar o que diz esse autor referente ao aprendizado da língua materna.

Esses gêneros do discurso nos são dados quase da mesma forma que nos é dada a língua materna, a qual dominamos livremente até começarmos o estudo teórico da gramática. A língua materna - sua composição vocabular e sua estrutura gramatical - não chega ao nosso conhecimento a partir de dicionários e gramáticas [sic] mas de enunciações concretas que nós mesmos ouvimos e nós mesmos reproduzimos na comunicação discursiva viva com as pessoas que nos rodeiam (BAKHTIN, 2003, p. 282-283).

Bakhtin, já na metade do século passado, apontava o emprego da língua, e não sua gramática normatizadora, como balizador do ensino de língua materna. Aliás, Saussure fez isso muito antes. Então, o que impede o professor de, 
efetivamente, propor situações enunciativas, por meio das quais os alunos possam aprender diferentes usos orais e escritos de sua língua mãe? Como em todo o fenômeno complexo, uma pergunta dessa natureza tem várias hipóteses de resposta. O que tenho abordado neste artigo vai em direção a uma delas.

Gostaria de finalizar esse conciso percurso teórico com a oposição feita por Ducrot entre texto e discurso. Creio ser a sistematização feita por esse semanticista a que melhor pode fundamentar o que venho propondo hic et nunc.

A relação estabelecida por Ducrot (1984) entre texto/discurso e por ele mantida ao longo de seus estudos (cuja base, segundo ele mesmo, está na oposição metodológica língua/fala, de Saussure) advém da distinção por ele sugerida entre material linguístico e realização linguística. Vamos a ela.

Material linguístico, consoante o autor, corresponde à língua saussuriana, um sistema de entidades abstratas, o qual persiste na variedade e na diversidade de usos que o falante faz de uma dada língua. Contrastivamente, realização linguística (equivalente à fala, em Saussure) é o que pode ser observado pelo linguista, uma vez que é a manifestação, a atualização, pelas produções do falante, daquelas entidades abstratas que constituem o material linguístico do qual ele lança mão para suas interlocuções consigo mesmo, com os outros e com o mundo.

A partir daí, Ducrot (1984) define, na mesma relação de oposição, frase / enunciado: (a) frase (e, analogamente, aqui, texto), como a entidade abstrata, de nível teórico-metodológico, criada pelo linguista ${ }^{9}$ para descrever o sentido dos enunciados produzidos por meio de uma dada língua, uma vez que frase, como material linguístico que é, subsiste às diferentes realizações que dela faz 0 enunciado; e (b) enunciado (equivalente ao que chamo, no âmbito deste artigo, discurso), como manifestação datada, circunstancial, isto é, produzida pelos falantes em um lugar e um tempo determinados, entidade concreta, realidade empírica, uma das múltiplas possibilidades de realização da frase.

O semanticista (1984) defende ${ }^{10}$ a ideia de que a realização linguística seja ela entendida como o que é realizado (o enunciado ou o discurso), como acontecimento (a enunciação), ou ainda como o processo de produção (a atividade linguística - ocorre em dois níveis: o nível elementar, constituído pela frase e pelo enunciado, e o nível complexo, formado pelo texto - entendido como sequência ${ }^{11}$ de frases, logo, igualmente uma entidade abstrata subjacente aos discursos realizados - e pelo discurso - como sequência de enunciados interligados, por isso, uma entidade concreta, uma manifestação/ realização do texto.

Como eu dizia em Azevedo (2006, p. 120), é preciso acrescentar ao que foi dito

[...] não é a quantidade de enunciados, mas a forma como se relacionam que faz de um discurso uma realização lingüística de nível complexo, uma organização semanticamente sistêmica, quer pela intrincada rede de 
relações que a configura, quer pela unicidade que essa rede lhe confere (AZEVEDO, 2006, p. 120).

É com base nas oposições expostas brevemente nesse tópico, valendo-me dos pressupostos teóricos elencados, que penso ser possível alinhavar algumas conjecturas acerca do ensino de língua, mais especificamente, da modalidade escrita da língua. Quando digo "alinhavar", é porque as ideias aqui sugeridas não teriam como, até pelas características próprias de uma publicação como esta, receber o tratamento adequado em termos de aprofundamento e detalhamento. $\mathrm{E}$, quando menciono "conjecturas" é justamente pelo fato de, ainda, carecerem de maior estudo e validação para ultrapassarem esse estágio.

\section{Considerações que não são finais}

Como sinalizei inicialmente, a maior finalidade do que trouxe aqui é a de lançar à discussão, junto a professores e pesquisadores, algo que parece ser uma nova moda no ensino da língua materna: o estudo dos gêneros de texto.

Essa discussão, no meu modo de pensar, teria um bom início se seu ponto de partida fosse o conhecimento produzido pela ciência Linguística, por meio das teorias da enunciação e do discurso, começando pelos pressupostos saussurianos.

Entendo que aprender uma língua é, essencialmente, desenvolver habilidades e que, para isso, faz-se mister usar efetivamente essa língua, quer em termos de produção, quer de recepção, seja oralmente ou por escrito, em diversos tempos e espaços, vestindo a roupagem de diversos locutores com variados propósitos para seus discursos e interagindo com diferentes alocutários.

Em contrapartida, ensinar o uso de uma língua requer, antes de tudo, concebê-la como uma organização sistêmica, dinâmica, em que os seus constituintes somente têm existência na relação de oposição com todos os outros componentes do mesmo sistema. Com efeito, se os professores em geral, ou ao menos os de língua materna, entendessem o que significa um sistema linguístico e as relações de oposição que o engendram, nunca mais teríamos a normatização e a nomenclatura gramatical regendo e norteando o processo de ensino.

É urgente pararmos de pensar que o uso proficiente de uma língua, materna ou estrangeira, oralmente ou por escrito, é privilégio daqueles que nasceram com o "dom da palavra". E, por outro lado, parar de avaliar o desempenho dos alunos pela memorização de regras e classificações gramaticais.

Com base em todas essas concepções, reflexões, discussões acerca do ensino e da aprendizagem de língua, proponho que, desde o período de alfabetização até, no mínimo, o final do ensino fundamental, a promoção do desenvolvimento das habilidades de falar, compreender o que é ouvido, escrever e ler seja pautada pela análise dos textos e pela produção 
dos discursos, no sentido ducrotiano do termo, de uma dada língua. Dito de outra forma, creio que a explicitação das estruturas sintático-semânticas e enunciativas disponíveis no sistema linguístico possa contribuir substancialmente para a realização, no sentido da produção (oral e escrita) e a recepção (leitura e compreensão do que é ouvido) dos discursos que mobilizam esse sistema.

Por que defendo a ideia de que esse trabalho com as entidades linguísticas abstrata e concreta, de nível complexo, respectivamente o texto e o discurso, precede o estudo dos gêneros de texto? A resposta é simples, malgrado a complexidade inerente à aprendizagem de uma língua: de nada adianta estudar, não necessariamente aprender, a configuração de um determinado gênero se não se aprende, antes, a compreender e a produzir a intrincada teia de inter-relações sintático-semânticas que constituem o todo sistemicamente organizado que é o discurso, como unidade de sentido.

Para finalizar, uma ressalva quase óbvia: para que o cenário fashion do ensino de língua dê lugar à verdadeira promoção do desenvolvimento das habilidades que o uso de uma língua pressupõe, é premente a formação de professores que sejam realmente usuários proficientes dessa língua e que, simultaneamente, conheçam os pressupostos teórico-metodológicos referentes à enunciação e ao discurso.

\section{L'enseignement des genres? \\ Résumé}

Le fait d'enseigner à lire et à écrire semble être la finalité la plus importante de l'enseignement de langue maternelle dans l'Éducation Basique au Brésil, même si ceci est assumé de façon subliminale. Malgré toute la production scientifique-pédagogique et linguistique existante sur l' alphabétisation et la littératie , j' ai l'intenton, dans cet article, de poser quelques questions et de dechaîner quelques discussions sur l'apprentissage, en response à l'enseignement de la lecture et de la production écrite de textes/ discours. Ce serait l'enseignement des genres textuels/discoursifs le chemin le meilleur pour arriver au dévéloppement des complexes habilités de lire et d'écrire? Qu'est-ce qu'on aurait besoin d'enseigner pour que ces habilités soient, au moins satisfactoirement, developpées, des genres, des types, des séquences, des modes d'organisation du texte/discours? Celles-ci sont quelques unes des questions guides de la réfléxion ci-présentée à la lumière des auteurs tels que Saussure, Benveniste, Bakhtin e Ducrot.

Mots clés: Enseignement de langue maternelle. Lecture et écriture. Texte et discours. Genres textuels/discoursifs.

\section{Notas}

1 Como serão, na sequência, diferenciados texto e discurso, optei pela grafia gêneros textuais / discursivos neste momento do artigo. 
2 Cujo ensino, de minha parte, somente ocorreria no ensino médio.

3 Doravante, para diferenciar o texto que é efetivamente de autoria de Saussure, os "Escritos de Lingüística Geral”, daquele editado por Charles Bally e Albert Sechehaye, o "Curso de Lingüística Geral”, usarei ELG para o primeiro, e CLG para o segundo.

4 Tomo essa expressão emprestada de Ducrot (1984). Ainda neste artigo, apresentarei a distinção feita por Ducrot entre os níveis abstrato e concreto da realização linguística.

5 Mais adiante veremos que essa mesma distinção embasa a diferença texto/discurso ou gêneros de texto/gêneros de discurso.

6 Cito aqui a tradução que consta em Adam (2008, p. 30) por julgá-la mais adequada do que aquela do ELG.

${ }^{7}$ Usarei PLG como sigla de "Problemas de linguística geral" seguido dos numerais romanos I ou II que indicam o volume referido.

8 Veremos a seguir como Ducrot propõe tratar os níveis abstrato e concreto da realização linguística.

9 Ou por ele abstraída da observação das realizações produzidas pelos usuários da língua em questão.

10 O que creio ser válido inclusive para a versão mais recente da Semântica Argumentativa, a Teoria dos Blocos Semânticos.

11 Sequência, na teoria ducrotiana, não deve ser entendida como ordem ou soma, mas como segmento, conjunto sistêmico, isto é, um todo cujas partes estão intimamente relacionadas e impossível de ser assim reconhecido, senão pela interdependência de seus constituintes.

\section{Referências}

ADAM, Jean-Michel. A linguística textual: introdução à análise textual dos discursos. São Paulo: Cortez, 2008.

AZEVEDO, Tânia Maris de. Em busca do sentido do discurso: a semântica argumentativa como uma possibilidade para a descrição do sentido do discurso. Caxias do Sul, RS: EDUCS, 2006.

BENVENISTE, Émile. Problemas de lingüística geral II. Campinas, SP: Pontes, 1989.
BAKHTIN, Mikhail. Estética da criação verbal. São Paulo: Martins Fontes, 2003.

BOUQUET, Simon. Introdução à leitura de Saussure. 2. ed. São Paulo: Cultrix, 2001.

BRONCKART, Jean-Paul. Atividade de linguagem, textos e discursos: por um interacionismo sócio-discursivo. Tradução de Anna Rachel Machado e Péricles Cunha. São Paulo: EDUC, 1999.

FLORES, Valdir. Discurso. In: FLORES, Valdir et al. Dicionário de linguística da enunciação. São Paulo: Contexto, 2009. p. 83-84.

DUCROT, Oswald. La semántica argumentativa: una introducción a la teoría de los bloques semánticos. Buenos Aires: Ediciones Colihue, 2005. tes, 1987.

$O$ dizer e o dito. Campinas, SP: Pon-

Enunciação. In: Enciclopédia EI-

NAUDI: Linguagem-Enunciação. Lisboa: Imprensa Nacional-Casa da Moeda, 1984. Linguagem - Enunciação, p. 368-393. v. 2.

FLORES, Valdir. Enunciado. In: FLORES, Valdir et al. Dicionário de linguística da enunciação. São Paulo: Contexto, 2009. p. 107.

FLORES, Valdir. Língua. In: FLORES, Valdir et al. Dicionário de linguística da enunciação. São Paulo: Contexto, 2009. p. 150.

MORIN, Edgar. O método 3: o conhecimento do conhecimento. Porto Alegre: Sulina 1999.

SAUSSURE, Ferdinand de. Escritos de lingüística geral. São Paulo: Cultrix, 2009. (Organizado e editado por Simon Bouquet e Rudolf Engler com a colaboração de Antoinette Weil).

. Curso de lingüística geral. 20. ed. São Paulo: Cultrix, 1995.

FLORES, Valdir. Texto. In: FLORES, Valdir et al. Dicionário de linguística da enunciação. São Paulo: Contexto, 2009. p. 230. 